\title{
Clinical practice of minimally invasive gynaecological surgeries
}

\author{
Binaya Raj Bhandari', Ranjana Shrestha ${ }^{2}$, Binita Pradhan ${ }^{3}$ \\ ${ }^{1}$ Department of Obstetrics and Gynaecology, MIDAT Hospital, Lalitpur, Nepal \\ ${ }^{2}$ Department of Obstetrics and Gynaecology, Kathmandu Model Hospital, Kathmandu \\ ${ }^{3}$ Department of Obstetrics and Gynaecology, Patan Academy of Health science, Lalitpur \\ Correspondence: Dr Binaya Raj Bhandari, Department of Obstetrics and Gynaecology,
}

Email: bhandaribinaya9@gmail.com

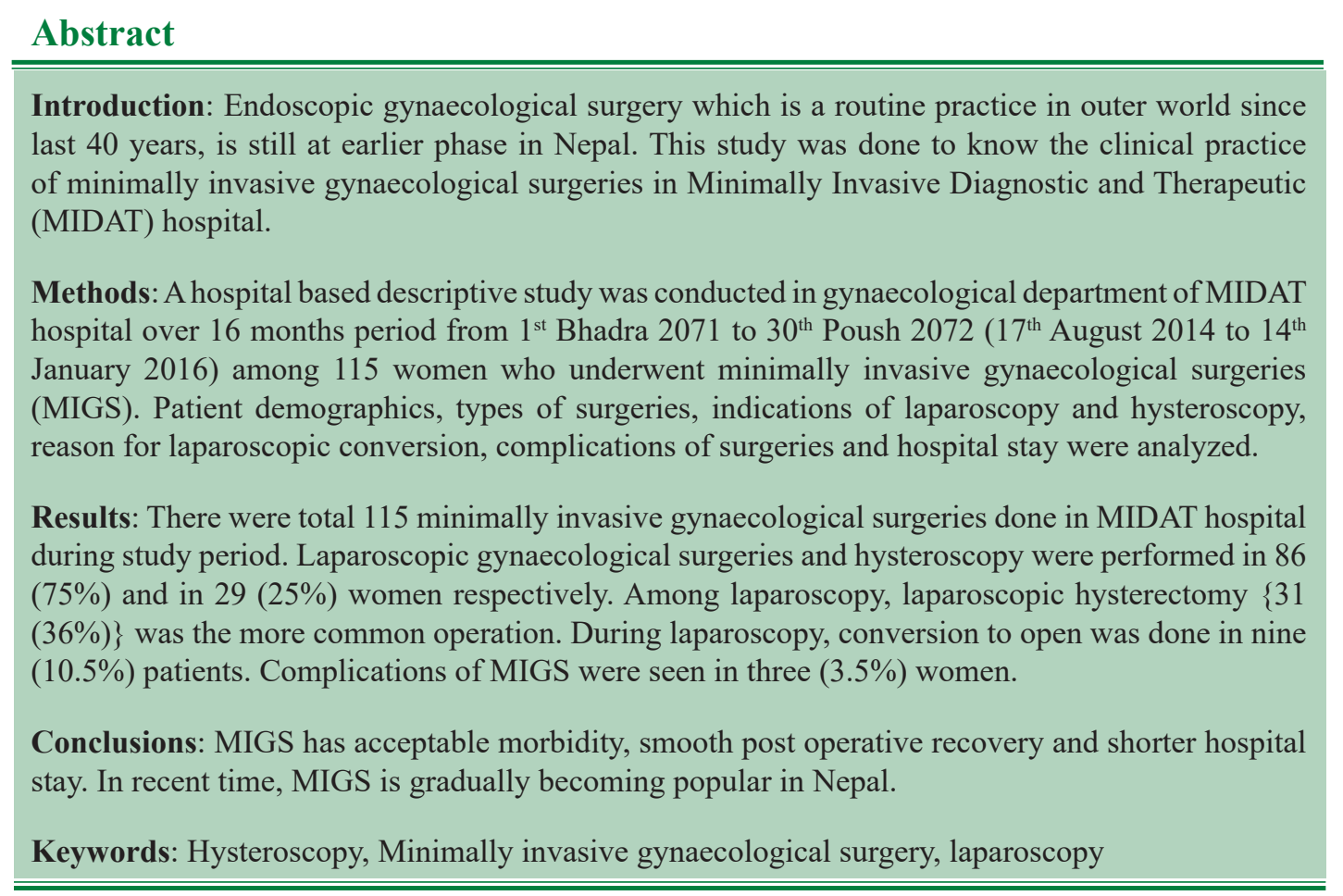

\section{Introduction}

Hysteroscopy was the first gynaecological endoscopic procedure performed when Pantaleoni used a cystoscope to identify uterine polyps in 1869. Laparoscopy was first performed by Jacobaeus of Sweden in 1910, wherein a Nitze cystoscope, composed of a candle and a hollow tube, was used to illuminate the peritoneal cavity. Diagnostic laparoscopy can provide valuable clinical information in patients with acute and chronic pelvic and abdominal pain. Most surgeries traditionally performed by the abdominal or vaginal approach can now be performed laparoscopically. ${ }^{1}$

Hysteroscopy is a low-risk technique that uses the endocervical canal, the natural passageway of the body, to gain entry into the intrauterine environment. During the mid-1980s, hysteroscopy replaced blind dilatation and curettage as the standard procedure for precise diagnosis of intrauterine pathology. Every gynaecologist is required to learn the skills of hysteroscopy, just as every urologist surely must be an accomplished cystoscopist. ${ }^{2}$

The use of operative laparoscopy to complete some or all of the hysterectomy procedures has been grown rapidly. ${ }^{3,4}$ It is well accepted that laparoscopy offers superior tissue image and anatomic view of the abdominopelvic cavity. Patients are in favor of laparoscopic hysterectomy because of its smaller incisions, less postoperative pain and discomfort, shorter hospital stay and quicker return to normal activity. 
Different types of gynaecological endoscopic surgeries are being practiced in many medical centers in Nepal. But there should be encouragement and support for upgrading the skill and practice on laparoscopic and hysteroscopic procedure. This study aimed to assess the practice of minimally invasive gynaecological surgeries in MIDAT hospital, Lalitpur, Nepal.

\section{Methods}

A hospital based descriptive study was conducted in gynaecological department of MIDAT hospital over 16 months period from $1^{\text {st }}$ Bhadra 2071 to $30^{\text {th }}$ Poush 2072 (17 $7^{\text {th }}$ August 2014 to $14^{\text {th }}$ January 2016) among 115 women who underwent minimally invasive gynaecological surgeries (MIGS).

Women with gynaecological disorder who were fit for minimally invasive surgeries were included for the study. Huge multiple fibroid uterus, suspected ovarian malignancy, anticipated dense pelvic adhesion, disease with unstable haemodynamic status and patients refused to give written consent were excluded for the study.

Ethical clearance for the study was taken from administration of MIDAT hospital. Including Consent for conversion to open, written consent was taken from the each participant. Laparoscopy was carried out under general anaethesia. Primary port was in the infraumbilical region. Hassen's open technique was used for opening the primary port. Desired pneumoperitoneum was created by $\mathrm{CO}_{2}$. Under laparoscopic guidance, required accessory ports were opened. Standard laparoscopic techniques were used for individual pelvic pathology. Monopolar coagulation, bipolar coagulation and dissecting scissor were used for laparoscopic surgery. Conversion to laparotomy was done in technically difficult surgeries and uncorrected intraoperative complications. Required post-operative care was provided to patients underwent laparoscopic surgery. Office hysteroscopy was done under local anaesthesia by using normal saline as distension media. Patient demographics, types of surgeries, indications of laparoscopy and hysteroscopy, reason for laparoscopic conversion, complications of surgeries and hospital stay were recorded. Quantitative data were analyzed using Statistical Package for Social Studies (SPSS) version 15.

\section{Results}

During the study period of 16 months, 115 women who had undergone minimally invasive gynaecological surgeries were included in the study. The mean age of the patient was $35.6 \pm 10.51$ years with minimum age of 17 years and maximum age of 78 years. Approximately 53 (46\%) patients were from Newar community and 28 (24.3\%) from Brahmin and Chhetri community (Table 1).
Table 1: Patient demographics

\begin{tabular}{l|l|l} 
Characteristics & Frequency & Percent \\
Age & & \\
$<19$ & 3 & 2.6 \\
$20-29$ & 34 & 29.5 \\
$30-39$ & 39 & 34 \\
$40-49$ & 26 & 22.6 \\
$>50$ & 13 & 11.3 \\
Caste & & \\
Brahmin/Chhetri & 28 & 24.3 \\
Newar & 53 & 46 \\
Tamang/Rai/Lama & 19 & 16.5 \\
Gurung/Magar & 5 & 4.4 \\
Madheshi & 5 & 4.4 \\
Nepali/Pariyar & 5 & 4.4
\end{tabular}

The indications of laparoscopy were uterine pathology in $27(31.3 \%)$, ovarian pathology in 28 (32.5\%), ectopic pregnancy in $11(12.7 \%)$, chronic PID with TO mass in six $(6.9 \%)$, permanent sterilization in nine $(10.5 \%)$ and sub fertility evaluation in five $(5.8 \%)$ patients (Table 2$)$.

Table 2: Indications of Minimally invasive gynecological surgeries

\begin{tabular}{l|l|l} 
Indications of laparos copy & Frequency & Percent \\
Uterine pathology & 27 & 31.3 \\
Ovarian pathology & 28 & 32.5 \\
Ectopic pregnancy & 11 & 12.7 \\
Chronic PID with TO mass & 6 & 6.9 \\
Permanent sterilization & 9 & 10.5 \\
subfertility & 5 & 5.8 \\
Indications of hysteroscopy & & \\
Abnomal Uterine Bleeding & 14 & 48.27 \\
Thickened endometrium & 8 & 27.58 \\
Lterine anomaly & 2 & 6.89 \\
Missed Cu T thread & 2 & 6.89 \\
Bulky uterus & 1 & 3.44 \\
Cervical polyp & 1 & 3.44 \\
SOL in uterine cavity & &
\end{tabular}


The indications of hysteroscopy were abnormal uterine bleeding in $14(48.27 \%)$ women, thickened endometrium in eight (27.58\%), uterine anomaly in two (6.89\%), missed $\mathrm{Cu}-\mathrm{T}$ thread in two $(6.89 \%)$, bulky uterus in one $(1.16 \%)$, cervical polyp in one $(1.16 \%)$ and submucosal fibroid in one (1.16\%) woman (Table 2 ).

Laparoscopic hysterectomy was done in 31 (36\%) women, laparoscopic cystectomy in 12 (13.9\%), laparoscopic tubal ligation in nine $(10.5 \%)$, laparoscopic unilateral salpingectomy in nine $(10.5 \%)$, laparoscopic conversion to laparotomy in nine $(10.5 \%)$, laparoscopy and tubal patency test in five $(5.8 \%)$ and diagnostic laparoscopy in three $(3.5 \%)$ patients (Table 3$)$. Out of laparoscopic hysterectomy, there were $22(25.6 \%)$ total laparoscopic hysterectomy with bilateral salpingoophorectomy, 4 (4.6\%) total laparoscopic hysterectomy, 3 (3.48\%) laparoscopic assisted vaginal hysterectomy with bilateral salpingoophorectomy and 2 (2.3\%) laparoscopic assisted vaginal hysterectomy.

There were no complications seen in $83(96.51 \%)$ women with laparoscopic surgery. Bladder injury was detected after conversion to laparotomy for internal bleeding while doing laparoscopic hysterectomy in one $(1.16 \%)$ woman. Bowel injury was detected on $2^{\text {nd }}$ post-operative day of laparoscopic hysterectomy in one (1.16\%) woman and umbilical port site infection was seen in one $(1.16 \%)$ woman (Table 3). There was no complication seen in women with diagnostic hysteroscopy.

The reason for laparoscopic conversion to laparotomy was dense adhesion in seven $(8.13 \%)$ women, uncontrolled uterine bleeding in one $(1.16 \%)$ and suspected ovarian malignancy in one (1.16\%) woman (Table 4$)$.

The mean hospital stay of surgery was $2.07 \pm 0.892$ days with minimum of one day and maximum of seven days. After surgery, $57(66.27 \%)$ patients were admitted in hospital for 2 days, 15 (17.44\%) for 24 hours and 13 (15.11\%) patients for 3 days (Table 4 ).
Table 3: Types and complications of laparoscopic surgeries

\begin{tabular}{l|l|l}
\hline Types of laparoscopic surgeries & Frequency & Percent \\
\hline Laparoscopic hysterectomy & 31 & 36 \\
Laparoscopic cystectomy & 12 & 13.9 \\
Laproscopic tubal ligation & 9 & 10.5 \\
Laparoscopic salpingectomy & 9 & 10.5 \\
Conversion to laparotomy & 9 & 10.5 \\
Laparoscopic salpingoopherectomy & 8 & 9.3 \\
Laparoscopy and Tubal patency test & 5 & 5.8 \\
Diagnostic laparoscopy & 3 & 3.5 \\
Complications of laparoscopic surgeries & & \\
None & 83 & 96.51 \\
Bladder injury & 1 & 1.16 \\
Bowel injury & 1 & 1.16 \\
Port site infection & 1 & 1.16
\end{tabular}

Table 4: Reasons for conversion to laparotomy and hospital stay

\begin{tabular}{l|ll} 
Reasons for conversion to laparotomy & Frequency & Percent \\
\hline Dense adhesion & 7 & 8.13 \\
Uncontrolled uterine bleeding & 1 & 1.16 \\
Ovarian malignancy & 1 & 1.16 \\
Hospital stay & & \\
One day & 15 & 17.44 \\
2 days & 57 & 66.27 \\
3 days & 13 & 15.11 \\
7 days & 1 & 1.16
\end{tabular}

\section{Discussion}

In this study, $73(63.4 \%)$ patients were in between $20-40$ years of age and $26(22.6 \%)$ in between $40-49$ years of age with mean age of $35.6 \pm 10.51$ years. The mean age was $47.9 \pm 5.6$ years among total laparoscopic hysterectomy group in comparative study between laparoscopic and abdominal study. ${ }^{7}$ The mean age was $38.6 \pm 10.8$ years in 
105 female patients with abnormal uterine bleeding who were undergone diagnostic hysteroscopy aged between 21 to 61 years and $34.3 \%$ were in between $40-50$ years. ${ }^{8}$ The mean age was 31.7 years (range $18-47$ years) in 28 patients of laparoscopic dermoid removal. ${ }^{9}$ The mean age was 33 years with age ranges from 20-46 years among 48 patients of chronic pelvic pain undergone diagnostic laparoscopy. ${ }^{10}$ The mean age of the patients undergoing laparoscopic surgery was $30 \pm 7.48$ years (mean $\pm \mathrm{SD}$ ) with maximum patients in the age group of 25-29 years. ${ }^{11}$

In this series, laparoscopy for uterine pathology was done in $27(31.3 \%)$, for ovarian pathology in $28(32.5 \%)$ and for ectopic pregnancy in $11(12.7 \%)$ women. Laparoscopic hysterectomy was done in $31(36 \%)$ women, laparoscopic cystectomy in $12(13.9 \%)$, laparoscopic tubal ligation in $9(10.5 \%)$, laparoscopic unilateral salpingectomy in nine $(10.5 \%)$, laparoscopic conversion to laparotomy in nine $(10.5 \%)$, laparoscopy and tubal patency test in five $(5.8 \%)$ and diagnostic laparoscopy in three $(3.5 \%)$ patients. Out of laparoscopic hysterectomy, there were $22(25.6 \%)$ total laparoscopic hysterectomy with bilateral salpingoophorectomy, $4(4.6 \%)$ total laparoscopic hysterectomy, $3(3.48 \%)$ laparoscopic assisted vaginal hysterectomy with bilateral salpingoophorectomy and 2 $(2.3 \%)$ laparoscopic assisted vaginal hysterectomy.

There were 133 (32.5\%) laparoscopy surgeries done for uterine pathology, 94 (23\%) for ovarian pathology and 267 (65.4\%) for tubal pathology. In gynaecological laparoscopy, salpingectomy was done in $21(5.1 \%)$ women, cystectomy in $69(17 \%)$, myomectomy in $61(15 \%)$, laparoscopic assisted vaginal hysterectomy in $63(15.4 \%)$ and total laparoscopic hysterectomy in nine $(2.2 \%)$ women. ${ }^{12}$

In hysteroscopy, 14 (48.3\%) women had undergone for evaluation of abnormal uterine bleeding, 2 (6.8\%) for localization of missed thread and removal and 13 (44.8\%) for other cause. A study conducted among 243 females who were performed diagnostic and therapeutic hysteroscopy, $236(97.1 \%)$ were evaluated and treated for vaginal bleeding and 7 (2.9\%) for recurrent abortions. ${ }^{13}$

There was no complication seen in office hysteroscopy. In a study for complications of hysteroscopy, 14 (0.12\%) women developed uterine perforation in diagnostic hysteroscopy, $5(0.2 \%)$ women developed fluid overload in operative hysteroscopy and $19(0.75 \%)$ women developed uterine perforation in operative hysteroscopy. ${ }^{14}$

There were three (3.48\%) women who developed complication in laparoscopic surgery. Urinary bladder injury, small bowel injury and port site infection were found in one woman each. Re-operation was done in one woman for small bowel injury on second post-operative day. In a study of total laparoscopic hysterectomy, technique and complication of 830 cases, re-operative complications occurred in 38 $(4.7 \%)$ patients. Urologic injuries were observed in $23(2.6 \%)$ patients, intestinal injuries in $6(0.72 \%)$ and hemorrhagic complications were seen in $23(2.6 \%)$ patients. ${ }^{15}$

In hysteroscopy, none of the woman got admitted for overnight in the ward. In laparoscopic surgery, 57 (66.27\%) women were discharged on $2^{\text {nd }}$ post-operative day with mean hospital stay was $2.07 \pm 0.892$ days. One woman was admitted till $7^{\text {th }}$ post-operative day for re-operation after total laparoscopy hysterectomy due to small bowel injury. The mean hospital stay among total laparoscopic hysteroscopy was $1.2 \pm 0.4$ days, ranges from 0 to 3 days in a comparative study conducted between total laparoscopic and vaginal hysterectomy. ${ }^{16}$

\section{Conclusion}

Minimaly invasive Gynaecological surgery acceptable morbidity, smooth post operative recovery and shorter hospital stay. In recent time, MIGS is gradually becoming popular in Nepal.

\section{References}

1. Sharp HT, Francis SL, Murphy AA. Diagnostic and operative laparoscopy. In: Rock JA, Jones III HW, editors. Te Linde's Operative Gynaecology. $10^{\text {th }}$ ed. Philadelphia: Lippincott Williams \& Wilkins, a Wolters Kluwer; 2008. p. 319.

2. Baggish MS. Operative hysteroscopy. In: Rock JA, JONES III HW, editors. Te Linde's Operative Gynaecology. $10^{\text {th }}$ ed. Philadelphia: Lippincott Williams and Wilkins, a Wolters Kluwer; 2008. p. 336.

3. Merrill RM. Hysterectomy surveillance in United States, 1997 through 2005. Med Sci Monit. 2008; 14: CR 24-31.

4. Ishik-Akbay EF, Harmanill OH, Panganamamula UR, Aby M, Gaughan J, Chatwani AJ. Hysterectomy in obese women: a comparison of abdominal and vaginal routes. Obstet Gynecol. 2004; 104:710-4. https://doi.org/10.1097/01. AOG.0000140685.30899.24; PMid:15458890

5. Marana R, Busacca M, Zupi E, Garcea N, Paprella P, Catalano GF. Laparoscopically assisted vaginal hysterectomy versus total abdominal hysterectomy: a prospective, randomized, multicenter study. Am J Obstet Gynecol. 1999; 180:270-5. https://doi. org/10.1016/S0002-9378(99)70199-7 
6. McCracken G, Hunter D, Morgan D, Price JH Comparison of laparoscopic assisted vaginal hysterectomy, total abdominal hysterectomy and vaginal hysterectomy. Ulster Med J. 2006; $75: 54-8$

7. Balci O. Comparison of total laparoscopic hysterectomy and abdominal hysterectomy. J Turk Soc Obstet Gynecol. 2014; 4:224-7. https:// doi.org/10.4274/tjod.47108;

PMid:28913025 PMCid:PMC5558366

8. Allameh T, Mohammadizadeh F. Diagnostic value of hysteroscopy in abnormal uterine bleeding compared to pathology reports. Iranian Journal of Reproductive Medicine. 2007; 15(20):61-4.

9. Shawki O, Soliman I, Ebrashy A. Laparoscopic management of ovarian dermoid cyst. Middle East Fertility Society Journal.2004; 9(1):58-65.

10. Bajracharya J, Shrerstha NS, Karki C, Saha R. Laparoscopic findings in chronic pelvic pain. Journal of Kathmandu Medical College. 2012; 1(2):100-2. https://doi.org/10.3126/jkmc.v1i2.8146.

11. Saha R, Karki C. Laparoscopic management of benign ovarian masses. J Nepal Med Assoc. 2013; 52(192):608-11.
12. Parkar RB, Thagana NG, Baraza R, Otieno D. Experience with laparoscopic surgery at the AGA Khan hospital, Nairobi. East African Medical Journal. 2003; 8(1):44-50.

13. Fard SA, Ebrahimi FS, Montazeri F, Mashrabi O. Diagnostic features and therapeutic consequences of hysteroscopy in women with abnormal uterine bleeding and abortion. American Journal of Applied sciences. 2012; 9(1):13-7. https://doi.org/10.3844/ ajassp.2012.13.17.

14. Jansen FW, Vredevoogd CB, Ulzen KV, Hermans JO, Trimbos JB, Trimbo-Kemper TCM. Complications of hysteroscopy: a prospective multicenter study. Obstet Gynecol. 2000; 96(2):266-70. https://doi. org/10.1016/S0029-7844(00)00865-6; https:// doi.org/10.1097/00006250-200008000-00021 PMid:10908775.

15. O'Hanlan KA, Dibble SL, Garnier AC, Reuland ML. Total laparoscopic hysterectomy: technique and complications of 830 cases. JSLS. 2007; 11:45-53.

16. Mortan M, Cheung VYT, Rosenthal DM. Total laparoscopic versus vaginal hysterectomy: A retrospective comparison. J Obstet Gynaecol Can. 2008; 30(11):1039-44. https://doi.org/10.1016/S17012163(16)32999-1. 